\title{
Protective Effect of N-Acetyl Cysteine in Acrylamide-Induced Hepatotoxicity in Albino Rats
}

\author{
Amr Mohamed Younes ${ }^{1 *}$, MSc; Mohamed Abdel Hay Autifi ${ }^{2}$, MD; Hamdino Mohamed Attia ${ }^{1}$, MD
}

\begin{abstract}
* Corresponding Author: Amr Mohamed Younes

hamakey13@gmail.com

Received for publication October 4 2020; accepted November 9, 2020, published online November 9, 2020
\end{abstract}

Copyright 2020 The Authors published by Al-Azhar University, Faculty of Medicine, Cairo, Egypt. All rights reserved. This an openaccess article distributed under the legal terms, where it is permissible to download and share the work provided it is properly cited. The work cannot be changed in any way or used commercially.

\section{doi: 10.21608/aimj.2020.39891.1309}

${ }^{1}$ Department of Anatomy and Embryology, Faculty of Medicine (Damietta), Al-Azhar University. ${ }^{2}$ Department of Anatomy and Embryology, Faculty of Medicine, Al-Azhar University.

\begin{abstract}
Background: purification of drinking and wastewater needs acrylamide which is also used in sprays, paper, and pulp industry, and soil stabilizers, so it has a significant risk for our health Objective (Aim): studying the possible protective role of $\mathrm{N}$ acetyl cysteine against the hepatotoxic effect of acrylamide. Material and methods: The study was conducted at the Research Institute of Ophthalmology, Giza, and Electron Microscopic Unit at the Faculty of Agriculture, Cairo University, in the period between August 2018 and September 2018. Randomly divided forty male albino rats into four equal groups (10 rats each) were used: group I (control group), group II (sham control), group III (acrylamide-treated group): receiving $50 \mathrm{mg} / \mathrm{kg}$ body weight acrylamide by oral gavage daily for 21 successive days.

Group IV (acrylamide and $\mathrm{N}$-acetyl cysteine treated group) was received $50 \mathrm{mg} / \mathrm{kg}$ body weight acrylamide and $150 \mathrm{mg} / \mathrm{kg}$ body weight $\mathrm{N}$-acetyl cysteine both by oral gavage daily for 21 successive days Results: Group III showed disrupted hepatic architecture in comparison with groups I, II, and marked degenerative changes especially at portal triads, as well as in form of dilated sinusoids, pyknotic nuclei, and Ito cells. Group IV showed restoration of the normal hepatic architecture seen in control groups with an improvement of the degenerative changes.

Conclusions: Antioxidant effect of $\mathrm{N}$-acetyl cysteine reduces the oxidative stress of acrylamide and decreasing its hepatotoxic effects.

Keywords: N-acetyl cysteine; Acrylamide; Hepatotoxicity; Albino Rats.
\end{abstract}

\section{INTRODUCTION}

Cigarette smoking, eating sugar and potato chips, drinking water from flocculent-treated water and cosmetics all these are different ways of acrylamide exposure.

Acrylamide gained scientific interest when the World Health Organization reported that foods containing proteins and carbohydrates have a high concentration of acrylamide that formed during the healing process. Acrylamide at high doses produces multi-organ failure, especially at the liver cell. It decreases the hepatic protein level by leaking out of protein reserves from the hepatocytes. ${ }^{2}$

Acrylamide produces an oxidative stress-producing generation of reactive oxygen species causing oxidative damage that reduces the antioxidant defense systems. ${ }^{3}$

Antioxidants are substances either dietary as honey and green tea or others such as selenium, and $\mathrm{N}$ acetyl cysteine. Whatever their sources all enhance antioxidant enzymes thus maintaining the cell function. ${ }^{4}$

$\mathrm{N}$-acetyl cysteine is an antioxidant and is a precursor of glutathione. It can inhibit tumor growth or its metastasis and antagonizes oxidative stress that produced by acrylamide. ${ }^{5}$

Hence, the present study was designed to demonstrate the potential ameliorative effect of $\mathrm{N}$ - 
acetyl cysteine against the hepatotoxic effect of acrylamide.

\section{MATERIAL AND METHODS}

This study was conducted in the period between August 2018 and September 2018, at the Research Institute of Ophthalmology, Giza, and Electron Microscopic Unit at the Faculty of Agriculture, Cairo University.

Forty adult male albino rats weighing 200-230 gained from the animal house, Ophthalmology Research Institute, Giza, Egypt. The animals were kept in isolated cages (10 rats each) at room temperature and allowed water and food ad libitum. $\mathrm{N}$-acetyl cysteine was purchased from Mena Pharm Company as a bottle containing tablets $(600 \mathrm{mg}$ each). It was dissolved in distilled water and was given in a dose of $150 \mathrm{mg} / \mathrm{kg}$ body. ${ }^{6}$

Acrylamide was purchased from El Gomhorya Company, Egypt as a pure white powder gained in a bag weighing $500 \mathrm{~g}$. It is a water-soluble vinyl monomer. It was dissolved in distilled water and given in a dose of $50 \mathrm{mg} / \mathrm{kg}$ body weight by oral gavage.

The rats were randomly divided into four equal groups (10 rats each) as follows: The first two groups (I \& II) did not take any drugs otherwise the second group received $2 \mathrm{ml}$ of distilled water by oral gavage daily for 3 weeks. Group III (acrylamide-treated group) received $50 \mathrm{mg} / \mathrm{kg}$ body weight acrylamide by oral gavage daily for 3 weeks. ${ }^{8}$

Group IV (acrylamide and N-acetyl cysteine treated group) received $50 \mathrm{mg} / \mathrm{kg}$ body weight acrylamide and $150 \mathrm{mg} / \mathrm{kg}$ body weight $\mathrm{N}$-acetyl cysteine. Both drugs are given via oral gavage daily for 3 weeks. ${ }^{9}$

24 hours after the last treatment, all rats were sacrificed by cervical dislocation under ether anesthesia. The rat abdomen was opened by midline incision; then the liver was dissected out and washed in normal saline then cut into pieces about $3-5 \mathrm{~mm}^{3}$ for light microscope and $1 \mathrm{~mm}^{3}$ for the electron one. All experiments were approved by the ethical committee of Al Azhar University, Egypt
Specimens from each liver were fixed in $10 \%$ formalin and embedded in Paraffin. Sections of $5 \mu \mathrm{m}$ thickness were obtained on slides of glass and stained with hematoxylin and eosin, periodic acid Schiff (PAS), and Masson's trichrome stains, after that the slides were studied by light microscope. ${ }^{10}$

For electron microscope: Fixation of the liver specimen for 2 hours in 3\% glutaraldehyde at room temperature done. Then, they fixed for 2 hours in 1 $\%$ osmium tetraoxide at $4^{\circ} \mathrm{C}$. Then after washing the tissue three times in distilled water, we prepared the specimens for dehydration, infiltration, ultramicrotomy, and staining. ${ }^{11}$

For the histomorphometric study, Leica Qwin 500 LTD was used for this quantitative study. By using its image analyzer program, the pixels were converted to actual micrometer units then it measured the followings:

The area percent of collagen tissue fibers in sections stained with Masson's trichrome was examined in magnification X 100 and measured inside a standard measuring frame. In each selected field, fibers of collagen within the liver were put inside the standard measuring frame, and then it was hidden by a green binary color to be measured and expressed as an area percent in relation to the area of the standard measuring frame. ${ }^{12}$

In PAS stained sections, liver cell glycogen measurement (optical density) was done as follows: before hiding the positive areas by blue binary color, using magnification $x 400$, we turned the image into a grey image then we measured the frame to enclose the required area. ${ }^{13}$

Ten microscopic fields were selected randomly for each specimen. The obtained data were expressed as mean \pm SD and subjected to statistical analysis and exemplified in a table. The gained data were compared by one-way analysis of difference by using SPSS 22 program.

The significant data between diverse groups were compared. "P" values > 0.05 were considered significant and "P" values > 0.001 were of highly significance.
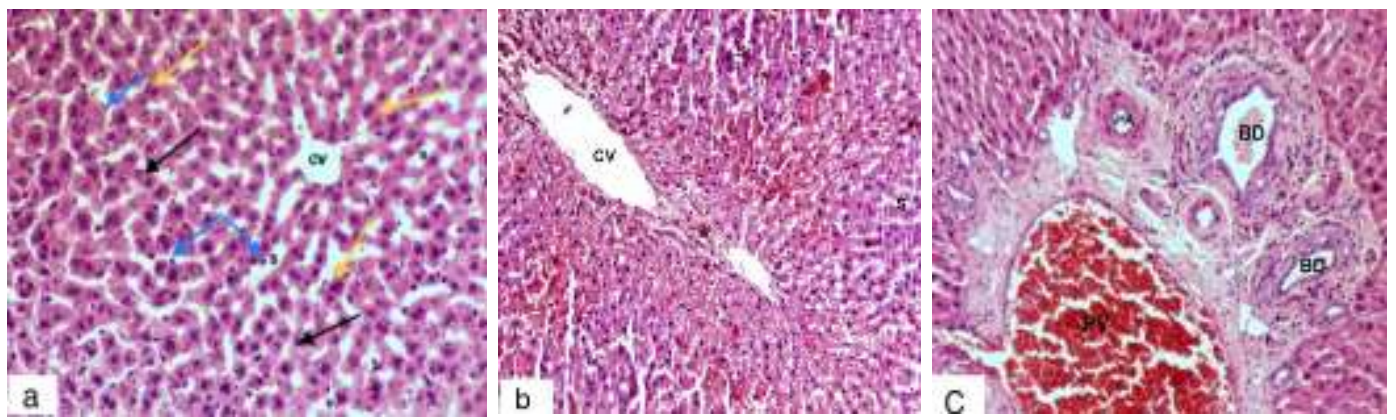

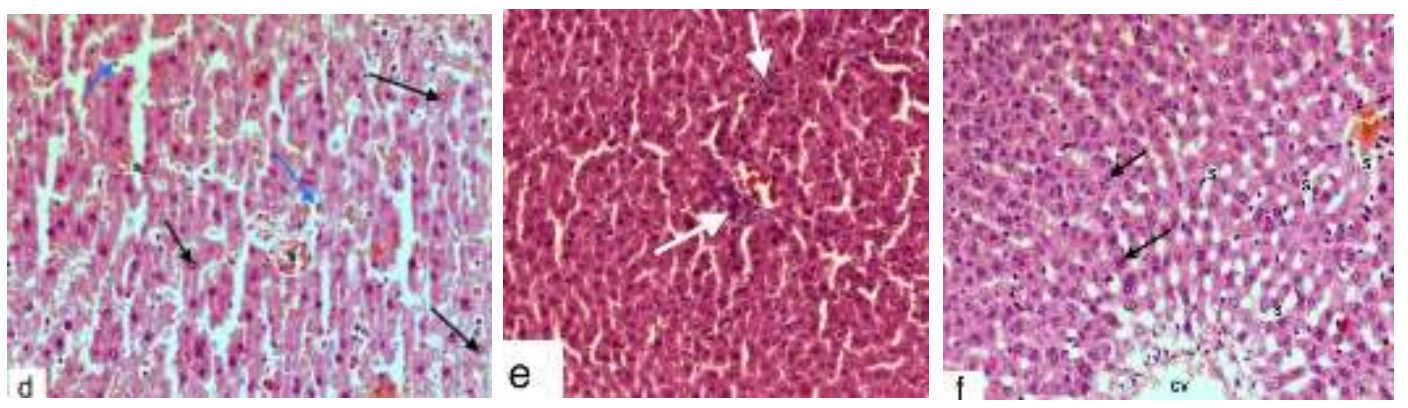

Fig.1: Photomicrographs of hematoxylin and eosin-stained sections of the liver of albino rat. CV = central vein, black arrows $=$ hepatocytes, yellow arrows $=$ binucleated hepatocytes, blue arrows $=$ Ito cells, $\mathrm{s}=$ sinusoids, $\mathrm{PV}=$ portal vein, $\mathrm{BD}=$ bile duct, $\mathrm{HA}=$ hepatic artery and white arrows = inflammatory cellular infiltration (all photomicrographs were with magnification X 400).

PAS reactions were strongly positive in groups I \& II (Figure 2a) and weak positive in group III (Figure 2b) while group IV was moderately positive (Figure $2 \mathrm{c}$ ).

Masson's trichrome stained sections showed collagen fibers deposition around the central vein and portal areas were minimal in group I \& II (Figure 2d) and were increased in group III (Figure 2e) while group IV showed a mild increase (Figure 2f).
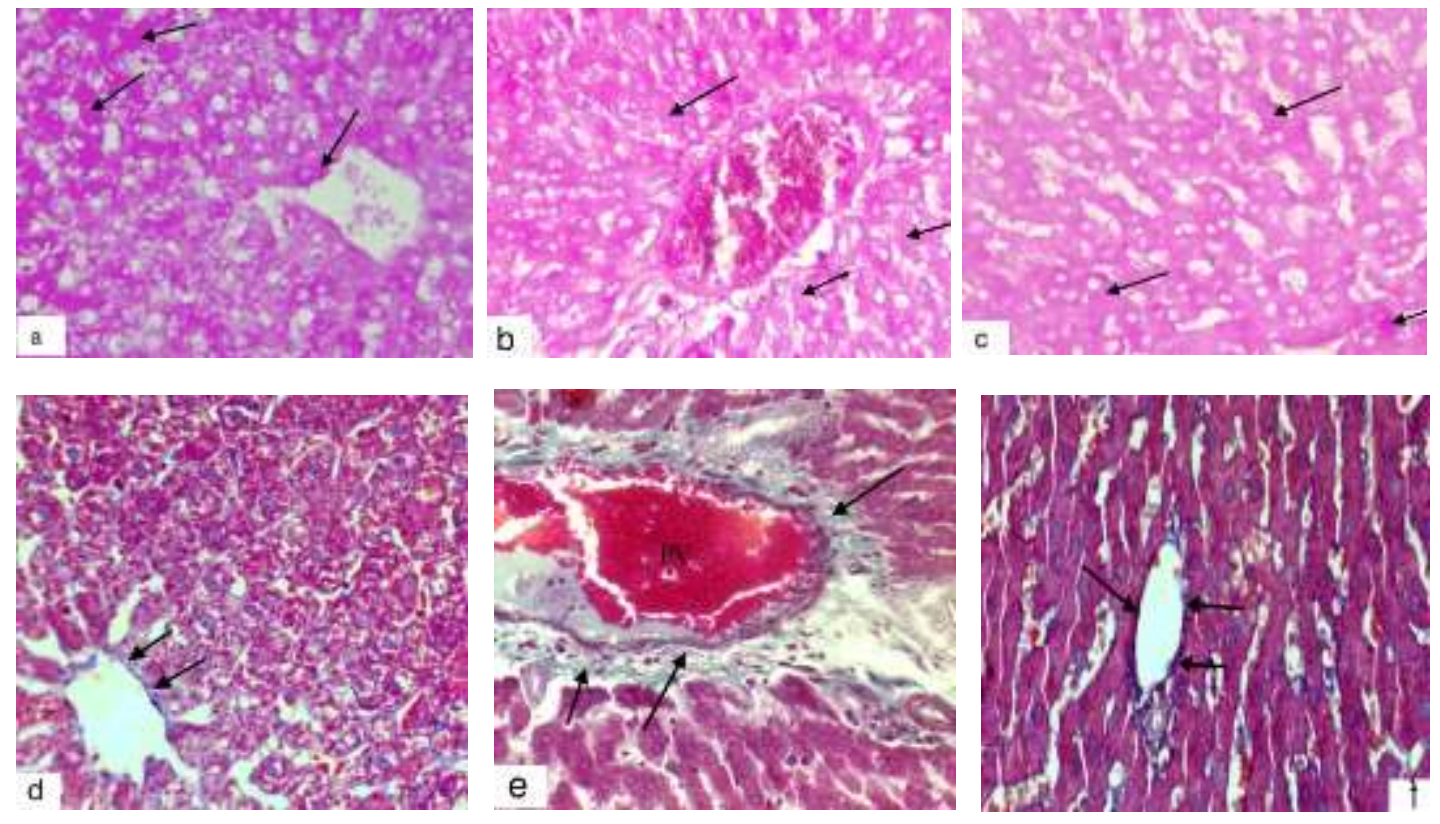

Fig. 2: A photomicrograph of a section of a rat liver showing PAS reaction of the cytoplasm of the hepatocytes (arrows) (a-c) and collagen fibers deposition in the portal area (arrows): (d-f). (All photomicrographs were with magnification X 400).

Electron microscopic specimens of group I \& II showed a rounded nucleus with a uniform nuclear envelope and peripheral (marginal) chromatin. The cytoplasm appeared granular, filled with numerous mitochondria and rough endoplasmic reticulum (Figure 3a).

Group III showed: a nucleus with an irregular nuclear envelope and a clumped chromatin. The cytoplasm appeared rarefied and filled with many rounded vacuoles and the absence of mitochondria (Figures 3b-d).

Group IV showed: a rounded nucleus with a uniform nuclear envelope and peripheral chromatin. The cytoplasm appeared filled with numerous mitochondria and rough endoplasmic reticulum (Figure 3e). 

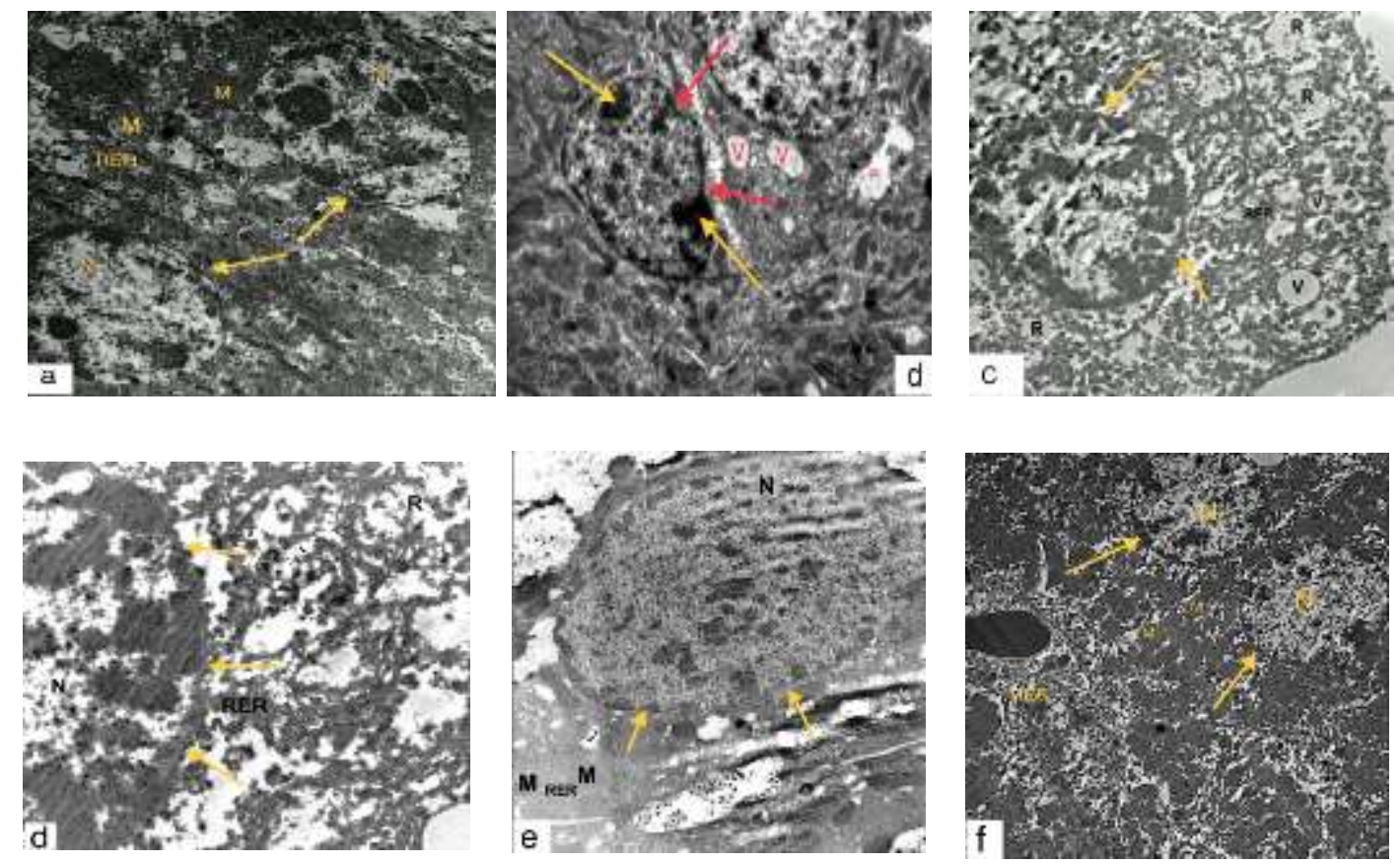

Fig. 3: Electron micrograph of the hepatocytes: $\mathrm{N}=$ nucleus, yellow arrows = nuclear envelope with its chromatin, red arrows = irregular nuclear envelope, $\mathrm{V}=$ vacuoles, $\mathrm{R}=$ rarefaction of cytoplasm, $\mathrm{RER}=$ rough endoplasmic reticulum, $M=$ mitochondria. $\mathrm{a}=($ TEM X 6000), $\mathrm{b}=($ TEM X 5000), $\mathrm{c}=($ TEM X $5000), d=($ TEM X 12000), $e=($ TEM X 10000) and $\mathrm{f}=($ TEM X 3000).

Statistically, the mean area of collagen fibers deposition showed non-significant variations between groups I, II, and IV. Meanwhile, group III was highly significant in comparison to the mean \pm SD of group I and II (table 1).

\begin{tabular}{|c|c|c|c|c|c|}
\hline Groups & & Group I & Group II & Group III & Group IV \\
\hline & Mean \pm SD & $1.246 \pm 0.12$ & $1.380 \pm 0.024$ & $4.210 \pm 0.034$ & $1.460 \pm 0.0124$ \\
\hline Group I & $1.246 \pm 0.12$ & & NS & & NS \\
\hline Group II & $1.380 \pm 0.024$ & NS & & $\leq 0.01 * *$ & NS \\
\hline Group III & $4.210 \pm 0.034$ & $\leq 0.01 * *$ & $\leq 0.01 * *$ & & $\leq 0.01 * *$ \\
\hline Group IV & $\begin{array}{c}1.460 \\
\pm 0.0124\end{array}$ & NS & NS & $\leq 0.01 * *$ & $\leq 0.01 * *$ \\
\hline
\end{tabular}

Table 1: showing mean collagen fibers deposition at different groups.

$\mathrm{P}^{*}$ : Significant $(\mathrm{p} \leq 0.05)$, $\mathrm{P}^{* *}$ : Highly significant $(\mathrm{p} \leq 0.01)$, NS: non-significant. SD: Standard deviation. 
The mean optical density of glycogen content in PAS stained liver sections demonstrated that group I and II data were statistically highly significant as compared with the same measurement of group III but non-significant as compared with measurements in group IV (Table 2).

\begin{tabular}{|c|c|c|c|c|c|}
\hline Groups & & Group I & Group II & Group III & Group IV \\
\hline & Mean \pm SD & $0.920 \pm 0.046$ & $0.860 \pm 0.042$ & $0.480 \pm 0.012$ & $0.850 \pm 0.026$ \\
\hline Group I & $0.920 \pm 0.046$ & …............ & NS & $\leq 0.01 * *$ & NS \\
\hline Group II & $0.860 \pm 0.042$ & NS & .............. & $\leq 0.01 * *$ & NS \\
\hline Group III & $0.480 \pm 0.012$ & $\leq 0.01 * *$ & $\leq 0.01 * *$ & ........ & $\leq 0.01 * *$ \\
\hline Group IV & $0.850 \pm 0.026$ & NS & NS & $\leq 0.01 * *$ & \\
\hline
\end{tabular}

Table 2: showing the mean optical density of glycogen at different groups.

$\mathrm{P}^{*}$ : Significant $(\mathrm{p} \leq 0.05), \mathrm{P}^{* *}$ : Highly significant $(\mathrm{p} \leq 0.01)$, NS: non-significant. SD: Standard deviation.

\section{DISCUSSION}

As acrylamide has various and different types of exposure particularly it is involved in food and drink, recent studies gave it some interest. ${ }^{1}$

Exposure to acrylamide leads to increase reactive oxygen species which in turn increases lipid peroxidation and markedly increases malondialdehyde that was used as an oxidative stress marker. ${ }^{8}$

In acrylamide treated rats, the antioxidant hepatic glutathione enzyme (GSH) was markedly decreased. GSH plays a protective role against cell damage and keeps the integrity of the cell. ${ }^{8}$

$\mathrm{N}$-acetyl cysteine plays a vital role in glutathione production that provides a defense mechanism against oxidative stress, it also a powerful cleaner of free radicals leading to the prevention of cell damage. ${ }^{14}$

Therefore our study was done to observe its hazards on the liver as it the main site of detoxification and how the anti-oxidant $\mathrm{N}$-acetyl cysteine antagonized these hazards.

Disruption of the normal histological structure in group III was similar to those recorded by Rahangadale et al. ${ }^{15}$ who noticed it in the form of condensed and shrinkage of Ito cells. These observations were mentioned before by Sahai et al. ${ }^{16}$ who added that pyknosis including all liver cells including hepatocytes, Ito cells, and phagocytic cells.

Hepatic sinusoids hyperemia and blood vessels hemorrhages were mentioned by Roodi et al, ${ }^{17}$ et al. as signs of acrylamide dangerous effects.

The irregularity of the nuclear envelope and condensation of its chromatin were confirmed by Liu et al. ${ }^{18}$ who also noted discrete spaces at the cytoplasm. These spaces were either the sites of active mitochondria or remnants of the rough endoplasmic reticulum.

AL-Mosaibih, ${ }^{19}$ kept his eyes on necrotic changes and reported that; high permeation of inflammatory cells especially around the portal triad. This permeation is interpreted by active Von Kupfer cells.

The weak positivity of PAS was compatible with the findings of Mohamed and Selim, ${ }^{20}$ who referred these findings to the consumption of glycogen granules. Kumar et al. ${ }^{21}$ proved our findings, as he found a high deposition of collagen fibers around the portal triad that explained this by stellate cell damage as it the main source of collagen.

Concerning group IV findings, they were in harmony with Altinoz et $a{ }^{22}$ and Cetinkaya et $\mathrm{al}^{23}$. They demonstrated the technique of hepatotoxicity as it is induced by free radicals that are prevented by the antagonistic action of $\mathrm{N}$-acetyl cysteine.

Abdo et al. ${ }^{24}$ reported that the portal triad and surroundings collagen fibers appeared nearly normal in rats received $\mathrm{N}$-acetyl cysteine, which is concordant to our study.

In group IV, our data was appropriate with those of Gordon et al. ${ }^{25}$ who assured that all cell organelles return nearly to normal including the rounded nucleus, the cytoplasm was filled with mitochondria and rough endoplasmic reticulum.

PAS reaction was moderate in group IV and that is convenient with the findings of Mohamed and Selim, ${ }^{20}$. The mean optical density of the same group was statistically not important when compared with the first two groups while it was highly important when compared with group III. 


\section{CONCLUSION}

In conclusion, changes in liver structure produced by acrylamide might be antagonized by the $\mathrm{N}$-acetyl cysteine antioxidant effect.

\section{REFERENCES}

1. Muttucumaru N, Powers S, Elmore S, et al. Acrylamide-forming potential of potatoes grown at different locations, and the ratio of free asparagine to reducing sugars at which free asparagine becomes a limiting factor for acrylamide formation. Food Chemistry, 2017; 220 (1): 76-86. DOI: $\underline{\text { 10.1016/j.foodchem.2016.09.199 }}$

2. Pingot D, Pyrzanowski K, Michałowicz J, et al. Toxicity of acrylamide and its metabolite. Medycyna Pracy, 2013; 64(2): 259-71.

DOI: $10.13075 / \mathrm{mp} .5893 / 2013 / 0022$

3. Lineback D, Coughlin J, and Stadler $H$. Acrylamide in foods: a review of the science and future considerations. National library of medicine, 2012; 3(1): 15-35. DOI: 10.1146/annurev-food022811-101114

4. Mahmoodi M, Mehranjani M, Shariatzadeh S, et al. N-Acetyl cysteine improves function and follicular survival in mice ovarian grafts through inhibition of oxidative stress. Reproductive biomedicine Online, 2015; 30(1): 101-10. DOI: org/10.1016/j.rbmo.2014.09.013

5. Samunia Y, Goldsteinb S, and MichaelBerk D. The chemistry and biological activities of $\mathrm{N}$ acetylcysteine. Biochimica et Biophysica Acta (BBA), 2013; 1830 (8): 4117-129. DOI: 10.1016/j.bbagen.2013.04.016

6. Daneshpoya F, Karimipour M, Javanmard M, et al. Effects of N-acetyl cysteine on ovarian tissue auto grafted into granulation tissue compared to back muscle in rats. Turkish Journal of Medical Sciences, 2017; 47(3): 1931-9. DOI: 10.3906/sag-1704-170

7. Shan XL, Ning C, Cui-li Z, et al. Effect of subchronic exposure to acrylamide induced on the expression of bcl-2, bax and caspase- 3 in the rat nervous system. Toxicol., 2012; 217(1) : 46-53. DOI: 10.1016/j.etp.2015.11.007

8. Mehri S, Abnous K, Mousavi SH, et al. Neuroprotective effect of crocin on acrylamideinduced cytotoxicity in PC12 cells. Cell Mol Neurobiol 2012; 32(2):227-35. DOI 10.1007/s10571011-9752-8

9. Danilovic A, Lucon A, Srougi M., et al. Protective effect of $\mathrm{N}$ - acetyl cysteine on early outcomes of deceased renal transplantation. Transplantation Proceeding. 2011; 43(5), pp. 1443-9. DOI:10.3906/vet-1105-29

10. Hegazy R and Hegazy A. Hegazy' Simplified Method of Tissue Processing (Consuming Less Time and Chemicals). Annals of International Medical and Dental Research. 2015; 1 (2), 57-66.

11. Suvarna S, Layton C and Bancroft D. Bancroft's theory and practice of histological techniques. $8^{\text {th }}$ edition. E-Book. Elsevier Health Sciences; 2018. pp. 172-98.

12. Ross M and Pawlina, W. Histology a text and atlas. $7^{\text {th }}$ edition. Philadelphia: Wolters Kluwer; 2016. pp. 582-595.

13. Okamoto and Takahiro. Probability of axillary lymph node metastasis when sentinel lymph node biopsy is negative in women with clinically node negative breast cancer. A Bayesian approach. Breast cancer

DOI:10.2325/jbcs.12.203 2005;12(3):203-210.

14. Dhouiba E, Jallouli M, Annabi A .et al. A minireview on $\mathrm{N}$-acetylcysteine: An old drug with new approaches. National library of medicine, 2016; 151(15): 359-363. DOI: 10.1016/j.lfs.2016.03.003

15. Rahangadale S, Kurkure N, Prajapati B. et al. Neuroprotective effect of vitamin E supplementation in Wistar rat treated with acrylamide. Toxicol, 2012; 19(1): 1-8. DOI: 10.4103/0971-6580.94505.

16. Sahai V. Histological changes in liver of albino mice due to chronic administration of acrylamide. Ind. J. Fund. App. Life Sci, 2012; 2 (3): 51-54. DOI: $2090-0503$

17. Roodi P, Moosavi Z, Goli A. et al. Histopathological study of protective effects of honey on sub-acute toxicity of acrylamide induced tissue lesions, brain and liver. Iranian journal of toxicology, $\quad 2018 ; \quad 12(3)$ : $\quad 1-8$. http://ijt.arakmu.ac.ir/article-1-663-en.html

18. Liu D, Jin H, Tang C. et al. Sulfur dioxide: a novel gaseous signal in the regulation of cardiovascular functions. Medical Chemistry, 2010; 10(11): $1039-45$

DOI: $10.2174 / 1389557511009011039$

19. AL-Mosaibih M A. Effects of monosodium glutamate andacrylamide on the liver tissue of adult Wistar rats. Life Science Journal, 2013; 10(2): 35-42. DOI: 10.7537

20. Mohamed DA and Selim SA. Effect of perinatal acrylamide exposure on the liver of albino rat offspring: Light and electron microscopic study. Egyptian journal of histology, 2012; 35(3): 371-382. DOI: $10.23880 / \mathrm{JES}-16000114$

21. Kumar J, Srijit Das S, Teoh S. Dietary Acrylamide and the risks of developing cancer. Frontiers in nutrition, 2018; 5(14): 50-53. DOI: 10.3389/fnut.2018.00014

22. Altinoz E1, Turkoz Y and Vardi. The protective effect of $\mathrm{N}$-Acetyl cysteine against acrylamide toxicity in liver and small and large intestine tissues. 
National library of medicine, 2015; 116 (4): 252 258. DOI:/10.4149 bll_2015_0

23. Cetinkaya A1, Kantarceken B1, Bulbuloglu E. et al. The effects of L-carnitine and N-acetylcysteine on carbon tetrachloride induced acute liver damage in rats. National library of medicine, 2013; 114 (12): 682 - 688. DOI: 10.4149/BLL-2013-145

24. Abdo FK, Ahmed FF, Alazouny ZM. et al. Silymarin versus gold nanoparticles efficacy in ameliorating CCL4-induced liver fibrosis in adult male albino rats, A histological and Immunohistochemical study. British j. Sci., 2016; 13(2):13-32. DOI: 44519

25. Gordon G, Coleman W and Grisham J W. Temporal analysis of hepatocyte differentiation by small hepatocyte-like progenitor cells during liver regeneration in retro sine-exposed rats. American Journal of Pathology, 2000; 157(3):771-786. DOI:/10.1016S0002-9440(10)64591-9 